San Jose State University

SJSU ScholarWorks

Doctoral Projects

Master's Theses and Graduate Research

Spring 5-2016

\title{
Assessing Readiness for Interprofessional Learning about Sepsis among Registered Nurses, Physicians, and Respiratory Therapists in a Community Hospital
}

Katie Choy

California State University, Northern California Consortium Doctor of Nursing Practice

Follow this and additional works at: https://scholarworks.sjsu.edu/etd_doctoral

Part of the Other Nursing Commons

\section{Recommended Citation}

Choy, Katie, "Assessing Readiness for Interprofessional Learning about Sepsis among Registered Nurses, Physicians, and Respiratory Therapists in a Community Hospital" (2016). Doctoral Projects. 47. DOI: https://doi.org/10.31979/etd.rxb5-y5px

https://scholarworks.sjsu.edu/etd_doctoral/47

This Doctoral Project is brought to you for free and open access by the Master's Theses and Graduate Research at SJSU ScholarWorks. It has been accepted for inclusion in Doctoral Projects by an authorized administrator of SJSU ScholarWorks. For more information, please contact scholarworks@sjsu.edu. 
ASSESSING READINESS FOR INTERPROFESSIONAL LEARNING ABOUT SEPSIS AMONG REGISTERED NURSES, PHYSICIANS, AND RESPIRATORY THERAPISTS IN A COMMUNITY HOSPITAL

Interprofessional teamwork and education have been advanced as methods to address the complexities of patient care (National Academy of Medicine [NAM], 2011-2013). One area needing further exploration is health care professionals' readiness to learn together in the acute care setting. The application of interprofessional learning (IPL) focused on sepsis education and improvement in sepsis outcomes in a community hospital has not been fully assessed. This descriptive, quantitative study explored interprofessional readiness to learn, perceptions of professional identity, and understanding of roles and responsibilities, by examining three subgroups. Registered nurses $(n=52)$, physicians $(n=29)$, and respiratory therapists $(n=30)$ were assessed using the Readiness for Interprofessional Learning Scale (RIPLS). No statistically significant difference was observed in readiness level for IPL among the three subgroups. There was no relationship between age, gender, years of experience, and readiness level. This study provided a foundation that the subgroups studied were ready for IPL, therefore making IPL a viable option for curriculum development such as sepsis education.

\section{Katie Choy}

May 2016 


\title{
ASSESSING READINESS FOR INTERPROFESSIONAL LEARNING ABOUT SEPSIS AMONG REGISTERED NURSES, PHYSICIANS, AND RESPIRATORY THERAPISTS IN A COMMUNITY HOSPITAL
}

\author{
by \\ Katie Choy
}

\author{
A project \\ submitted in partial \\ fulfillment of the requirements for the degree of \\ Doctor of Nursing Practice \\ California State University, Northern Consortium \\ Doctor of Nursing Practice
}

May 2016 


\section{APPROVED \\ For the California State University, Northern Consortium Doctor of Nursing Practice:}

We, the undersigned, certify that the project of the following student meets the required standards of scholarship, format, and style of the university and the student's graduate degree program for the awarding of the master's degree.

Katie Choy

Project Author

\section{Lori Rodriguez $\mathrm{PhD}, \mathrm{RN}, \mathrm{CNE}$}

Lori Rodriguez, PhD, KN, CNE (Chair) SJSU Nursing Professor

Christmemtarver. DNP RN

Christine Tarver, DNP, RN, CNS, NEA-BC ECH Nursing Director

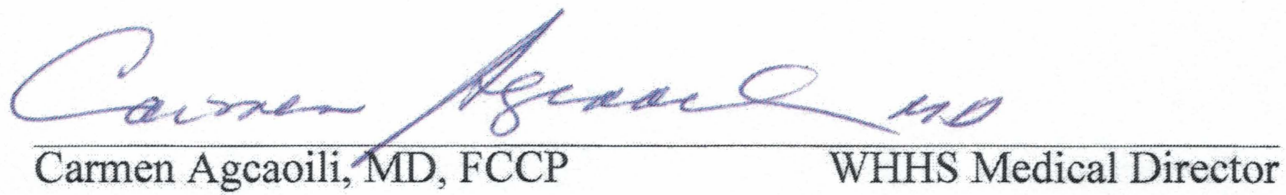




\section{AUTHORIZATION FOR REPRODUCTION OF DOCTORAL PROJECT}

$\underline{\mathrm{KC}}$ I grant permission for the reproduction of this project in part or in its
entirety without further authorization from me, on the condition that
the person or agency requesting reproduction absorbs the cost and
provides proper acknowledgment of authorship.

Permission to reproduce this project in part or in its entirety must be obtained from me.

Signature of project author: Natie Choy 


\section{ACKNOWLEDGMENTS}

I would like to express my heartfelt thanks to my committee for their mentorship and guidance. I sincerely thank my family, husband, and children for their encouragement and support. My heart is full gratitude for their love and patience as I pursued my dream. This manuscript is dedicated to my parents for their infinite wisdom. 


\section{TABLE OF CONTENTS}

LIST OF TABLES vii

LIST OF FIGURES viii

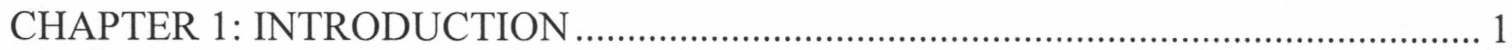

Statement of the Problem.........................................................2

The Complexity of Sepsis...................................................

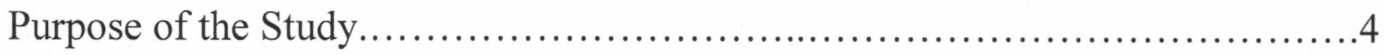

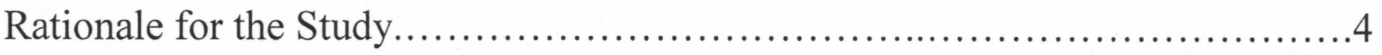

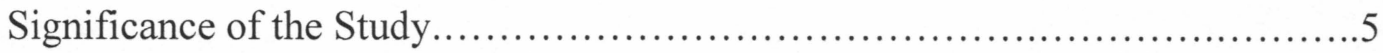

Theoretical Framework.........................................................

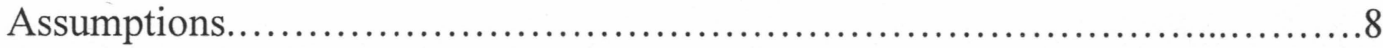

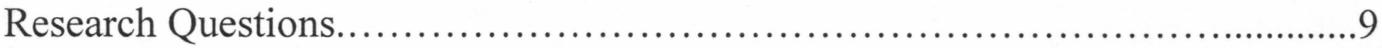

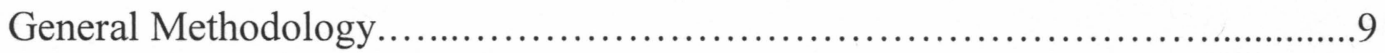

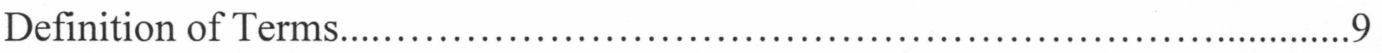

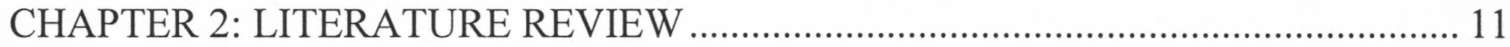

Interprofessional Team Approach to Sepsis...................................11

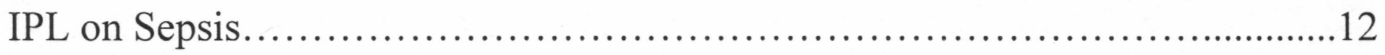

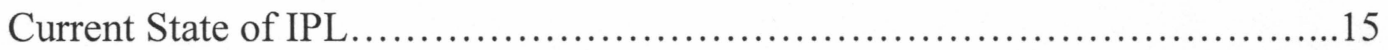

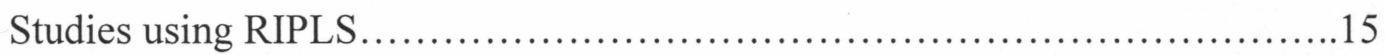

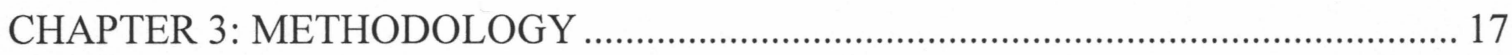

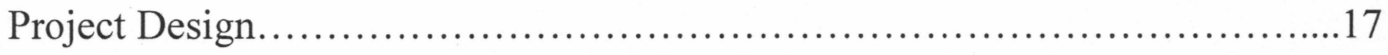

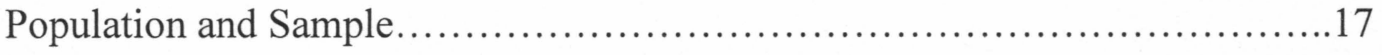

Demographic Variables.....................................................

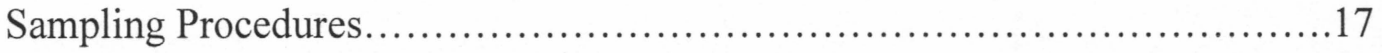

Investigative Techniques and Interventions..................................18 


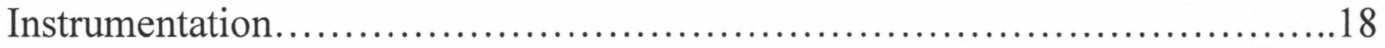

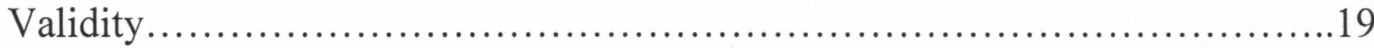

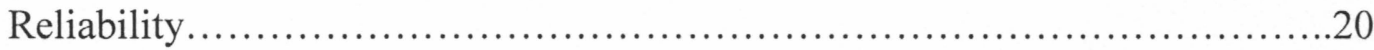

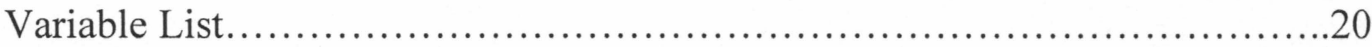

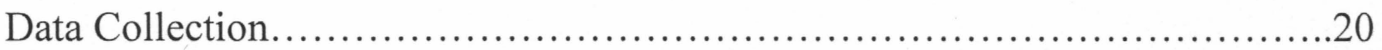

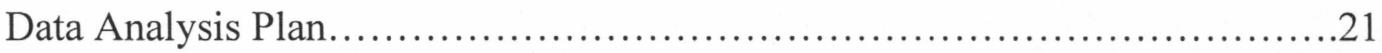

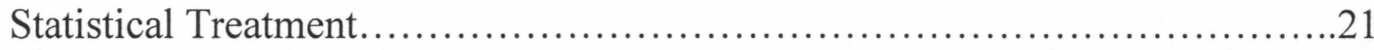

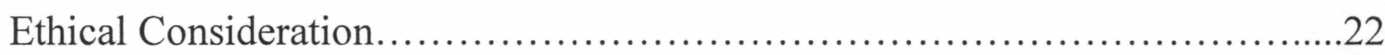

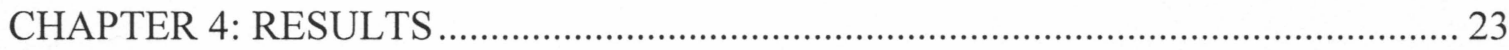

Demographic Description......................................................

Overall Readiness Level..................................................24

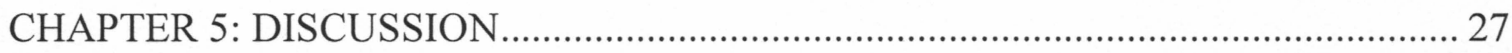

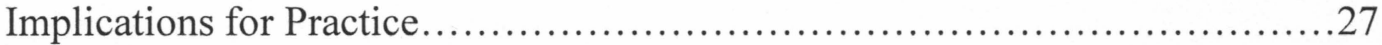

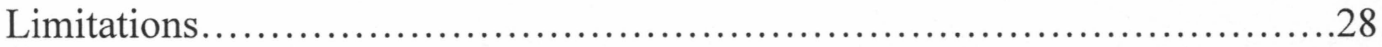

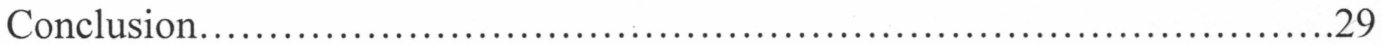

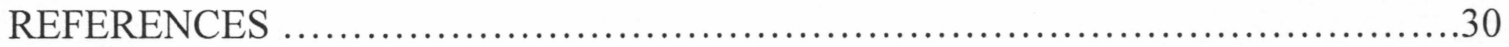




\section{LIST OF TABLES}

Table 1. Demographics by Profession.......................................23

Table 2. Readiness Level: Comparing Different Demographic Groups ..........25

Table 3. Readiness Level: Comparing Registered Nurses, Physicians, and Respiratory Therapists............................26 


\section{LIST OF FIGURES}

\section{Page}

Figure 1. Kolb's Experiential Learning Theory ............................... 7 


\section{CHAPTER 1: INTRODUCTION}

According to the National Academy of Medicine (NAM, 2015), the complexity of patients with hospitalized illness requires healthcare professionals to work together in a patient-centered collaborative manner. Sepsis is one example of a life-threatening condition that has a high morbidity and mortality necessitating an interprofessional approach to improve patient care. At the community hospital where this study was implemented, sepsis identification and management was adopted as a quality improvement initiative to improve sepsis mortality.

In order to improve sepsis outcomes, this study explored one aspect of the interdisciplinary approach: interprofessional learning (IPL). Three professions that work closely in managing the acute aspects of sepsis were surveyed for their readiness to learn together. Using the Readiness for Interprofessional Learning Scale (RIPLS) (Parsell \& Bligh, 1999; McFayden et al., 2005), a convenience sample of 111 nurses, physicians, and respiratory therapists were studied for their readiness to learn, perceptions of professional identity, and understanding of their professional role and the roles of others. The ultimate goal of this project was to inform on readiness for IPL in order to develop education in an IPL methodology on sepsis management to improve patient outcomes.

IPL provides participants opportunities to learn and practice skills that improve their ability to communicate and collaborate (NAM, 2011-2013). Multiple healthcare professional categories are expected to address the treatment and prevention of disease. Healthcare professionals are aware that interprofessional collaboration, communication, and teamwork are important for patient care and safety (Bajnok, Puddester, MacDonald, 
Archibald, \& Kuhl, 2012). Yet, even though there is awareness of the need for collaboration, it is unclear if many professionals are ready to learn together.

Studies on students in the healthcare professions show that when using IPL, students develop leadership qualities and respect for each other, which prepares them for work on teams and in settings where collaboration is a key to success (Reeves, Perrier, Goldman, Freeth \& Zwarenstein, 2013). Each profession brings a unique set of skills to the team. As a result, patients receive better, safer care and improved health outcomes (Reeves et al., 2013). It is uncertain, however, results of these student-focused studies translate to practicing healthcare professionals.

\section{Statement of the Problem}

Patient care has become increasingly complex. A patient may have a mix of acute and chronic disease, socio-economic issues, and issues with coping with their illness. Collaboration among healthcare professionals is required to meet these complex needs. IPL encourages collaboration by educating different professions together. While IPL has been proposed as a method to increase collaboration, there is a lack of evidence determining if healthcare professionals working in the acute care setting are ready and willing to learn together. There are few studies to date measuring the readiness for IPL among working professionals.

Healthcare professionals are expected to work together in teams. However, the challenge is that each profession has difficulty in understanding each other's professional roles (Pecukonis, 2014). Directives and recommendations introduced in several NAM reports support interdisciplinary teamwork to improve patient safety and processes of 
care. Effective IPL improves the quality of patient care. Thus, until recently, healthcare education has focused on each profession nurturing values and identity without the interaction between professionals that is required for teamwork.

While each profession provides something that somebody else cannot provide, each health profession has its own unique identity and pride in what it does. New methods of IPL have been introduced in universities across the country to teach the students of the professions to work together (Rossler \& Kimble, 2016). In the clinical practice setting, there are opportunities for different health professionals to work together and learn from each other's roles to improve patient outcomes. Yet the slow adoption of IPL in the acute care setting makes it unclear whether practicing professionals are ready to work together collaboratively.

IPL changes the dynamics between professionals and provides an opportunity for understanding how other health providers think. Nurse-physician collaboration is an important strategy for improving delivery of clinical care and organizational outcomes (World Health Organization [WHO], 2010). According to Sollami, Caricati, and Sarli (2015), poor interprofessional collaboration results in high dissatisfaction among professionals, increased resignations, and turnover. Nurses and physicians increasingly understand the importance of working together for healthcare outcomes. Yet, the differences that still remain between nurse and physicians require further effort to enhance relationships (Sollami et al., 2015). 


\section{The Complexity of Sepsis}

Sepsis is one of the most common medical diagnoses and leading causes of morbidity and mortality worldwide (Cooke \& Iwashyna, 2014). Sepsis accounts for nearly half of all hospital deaths and one of the most costly diagnoses to treat (Levy et al., 2010). Sepsis has a substantial impact on the health system and resources (LopezBushnell, Demaray, \& Jaco, 2014). As institutions around the country are held accountable in reporting quality outcomes to the Centers for Medicare and Medicaid Services (CMS), the sepsis core measure requirement has significance and relevance as it is tied to financial reimbursement (CMS, 2014). The clinical manifestations of sepsis can occur in other conditions as well making early detection difficult. Singer et al. (2016) reported an international task force updated definitions and clinical criteria for sepsis. Therefore, the interprofessional healthcare team collaboration is critical in early diagnosis, intervention, and treatment for sepsis.

\section{Purpose of the Study}

The purpose of this study was to conduct a readiness assessment for IPL, using the Readiness for Interprofessional Learning Scale (RIPLS), of registered nurses, physicians, and respiratory therapists in a community hospital. IPL opportunities are a critical component when teaching a highly relevant medical topic such as sepsis management (Chung, Medina, \& Fox-Robichaud, 2015).

\section{Rationale for the Study}

IPL provides opportunities for different professions to learn with, from, and about each other to improve collaboration and care delivery (Center for the Advancement of 
Interprofessional Education, 2002). The IOM's Global Forum on Innovation in Health Professional Education, formed in 2012, focused on the linkages between IPL and collaborative practice. IPL can help facilitate teamwork, communication and understanding between professions, and continuity of care (Cusack et al., 2012).

\section{Significance of the Study}

WHO (2010), NAM (2011-2013) and the IOM report, Future of Nursing: Leading Change, Advancing Health (2010) stress the importance of IPL to meet the burgeoning healthcare needs and complexities in the health care environment. The Institute for Healthcare Improvement (IHI) recognizes the importance of IPL as a tool used for achieving the IHI triple aim to achieve better patient care, health outcomes, and more efficient educational and health care systems (IHI, 2016). Furthermore, sepsis management is a CMS core measure and is significant for reimbursement related to provider documentation. Collaborative learning on sepsis has been used in continuous quality improvement. According to McKimm and Brake (2010), opportunities for formal and informal implementation of IPL exist in the workplace and should be relevant to all learners. Pitt, Kelley, and Carr (2014) implemented IPL in a community setting and concluded IPL should be integrated in clinical practice to improve working relationships and teamwork. This study is the next step of that continuous improvement process undertaken to examine the readiness to learn interprofessionally among professionals in a community hospital. 


\section{Theoretical Framework}

IPL has no consensus for a theoretical framework. In fact, due to the complexities of IPL, relevant theories are not mutually exclusive and it is difficult to select one theory among many (Hean, Craddock, \& O'Halloran, 2009). One theory described in the literature that is foundational to IPL is experiential learning. Experiential learning is a process of learning individually and in groups to engage collaboratively in real clinical situations (Owen et al., 2014). Cusack et al. (2012) identifies the experiential and interactive learning process of becoming part of an interprofessional team.

Experiential learning is one major learning theory related to adult learning. Malcom Knowles is the father of andragogy and provides assumptions required for adult learning. One of Knowles' assumptions is that adults are ready to learn the things that they need to know in order to do their job or deal with real life situations. Healthcare providers are in a constant learning mode to keep up with and professionally are committed to lifelong learning (Billings \& Halstead, 2012). Before learning together can occur, providers must be ready to learn together (NAM, 2015; CAIPE, 2002). Readiness to learn as a team occurs when people share a common goal of improving something. The learners must be open, willing, and able to participate in the learning process. In team learning if one or more parties are not open, ready and willing to learning, the learning process breaks down.

Experiential learning is a key element of IPL, because it involves learning together by sharing experiences, professional expertise, and perspectives on patient care, and clinical situations (McKimm \& Brake, 2010). David Kolb, Professor of 
Organizational Behavior, at Case Western Reserve University developed the experiential learning theory (ELT) in the 1970s. Kolb's ELT was built on the theoretical concepts of Dewey's pragmatism, Lewin's social psychology, Piaget's cognitive development, and Roger's client-centered therapy (Akella, 2010). Grounded in the humanist concept that people have the natural ability to learn, the ELT model emphasizes the learning process is a result of reflection and experience (Akella, 2010). The steps occur in sequence but can be entered at any point in time in the learning cycle. The four main stages in the learning process of ELT, as illustrated in Figure 1, are the following: 1) concrete experience, 2) reflective observation, 3) abstract conceptualization, and 4) active experimentation. Figure 1: Kolb's experiential learning theory

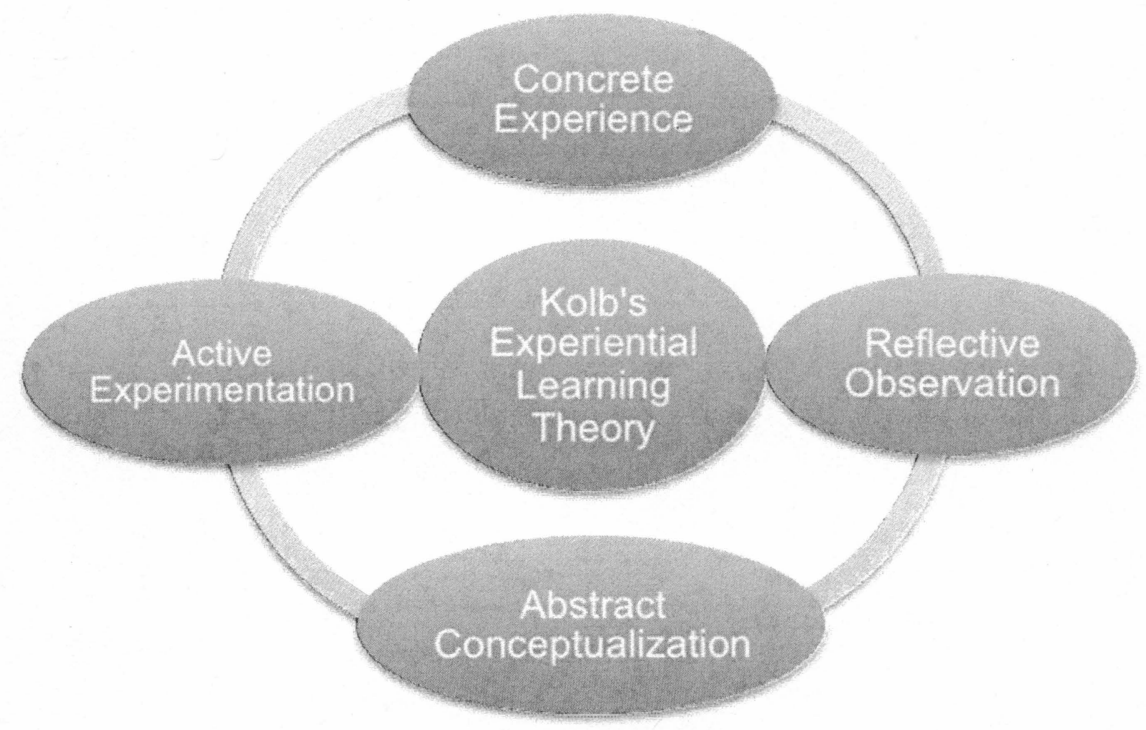

According to Kolb (1984), there are several assumptions in the learning process of Kolb's experiential learning theory:

- Learning is a continuous process, comes from one's experience and interaction with the environment, and results in knowledge creation. 
- During the concrete experience stage, the learner is actively involved in the educational activities and reflects on the experience in the reflective observation stage.

- In the abstract conceptualization stage, the learner uses analytical skills to understand the situation and problems.

- The learner acts on the new ideas gained from the experience to make learning meaningful in the active experimentation stage.

Kolb (1984) asserts that learning occurs in real life situations through collaboration on problem solving and decision-making. Puente (2015) points out interprofessional and integrated healthcare is the solution to the inefficient and costly current healthcare crisis. Working together and sharing expertise advances emerging initiatives to lower healthcare costs, increase efficiency, increase accountability, and consumer satisfaction (Puente, 2015). Students are being taught and encouraged to work collaboratively, but once they leave school they enter a healthcare environment that largely supports individual professional identity, blurred roles, and individual learning (Barwell, Arnold, \& Berry, 2013). IPL, while adopted by large teaching medical centers, lags in the smaller community hospital.

\section{Assumptions}

RIPLS tool is an accurate instrument. Participants answered the questions honestly. 


\section{Research Questions}

The research questions are aimed at analyzing the differences in the selected demographic factors in registered nurses, physicians, and respiratory therapists and their readiness toward IPL in the community hospital. The research questions are as follows:

1. What is the readiness level of registered nurses, physicians, and respiratory therapists for IPL in a community hospital?

2. Is there a statistically significant difference in readiness for IPL between registered nurses, physicians, and respiratory therapists?

3. Is there a relationship between age, gender, years of experience, and readiness level for each profession and overall?

\section{General Methodology}

A descriptive, quantitative design was used to examine the relationships between the independent variables of demographics and the dependent variables of readiness for IPL. The RIPLS instrument was used to measure and collect data on the readiness toward IPL (McFayden et al., 2005).

\section{Definition of Terms}

Discipline: A subset specialty of a profession.

Interprofessional: Interaction between professionals; for example, nurses, physicians, respiratory therapists.

Interprofessional learning (IPL): IPL is the overarching term often used interchangeably with interprofessional education and interprofessional practice. IPL is a 
contemporary method of learning by learners from two or more health and/or social care professions (NAM, 2015). IPL is the process of learning skills that build on current skills and develop enhanced roles (Wicker, 2011). IPL involves the active engagement of learners from different professions learning together (McKimm \& Brake, 2010). 


\section{CHAPTER 2: LITERATURE REVIEW}

There is growing body of literature exploring the role of IPL in preparing professionals to work in teams and suggesting functioning and collaborating interprofessional teams can carry out good sepsis care and management (Owen et al., 2014; Palleschi, Sirianni, O’Connor, Dunn, \& Hasenau, 2014; Chung et al., 2015). Therefore, included in the literature review are articles on IPL, interprofessional collaboration, and sepsis education.

\section{Interprofessional Team Approach to Sepsis}

In a study reported by Soo Hoo, Muehlberg, Rerraro and Jumaoas (2009), a multidisciplinary team was assembled with the goal of improving mortality of sepsis across 42 hospitals in one system. The team was made up of ED and critical care nurse leaders, an ED intensivist, quality and decision support leaders, a pharmacist, executive nurse leaders, and nurse educators. The team agreed on early identification as a goal. Education on sepsis, identification, monitoring, and pathophysiology were included. Managers, educators and clinical specialists delivered the education to staff. This team had to work around physicians by providing them with pre-printed orders and clearly stated that they were doing this to negotiate around hospital and medical staff approval of nurse driven care protocols. Meeting with a physician team, they agreed upon a pre printed order set.

The program was implemented and at the end of one year there was increased recognition of sepsis, and a $41.32 \%$ decrease in mortality, reduced length of stay, and $\$ 1,890,155$ cost savings. 
While the program was successful in meeting its goals, the implementation did not include the process of learning together. In fact, it pointed out that the physician group needed to be met with separately and the original multidisciplinary group had to devise a work around to get the order set through. Physicians educated physicians and nurses educated nurses, but no mention of other disciplines was made. Patient care improved but it unclear if a more integrated approach could yield even better results.

\section{IPL on Sepsis}

Owen et al. (2014) designed and implemented a continuing interprofessional education program (CIPE) to improve sepsis care at a large university medical center. The CIPE program focused on team-based sepsis care targeted physicians, nurses, and respiratory therapists who cared for patients with sepsis. The CIPL program included guidelines and management of patients with severe sepsis with emphasis on teamwork for time-dependent interventions. Using high fidelity simulation of sepsis cases, the learning activities consisted of the healthcare professionals' roles and responsibilities in providing effective sepsis care.

The mean pre- and post- scores on "attitudes related to IPL" did not change significantly in the RIPLS suggesting participants $(n=17)$ may have been positively biased and favorable towards IPL. The majority of participants were physicians and nurses. A limitation of this study was very few professionals from other disciplines were included. 
Owen et al.'s study (2014) evaluated the effects of IPL on healthcare team collaboration to improve sepsis care within the workplace setting. Results of this study revealed participants had greater appreciation for other team members and self-awareness of collaborative behaviors in their own practice. Teamwork is essential for optimal implementation of the complex and time-dependent interventions. Furthermore, collaboration is enhanced where sepsis care is delivered.

A research study by Palleschi et al. (2014) investigated if IPL improved the care of patients at risk for sepsis. Palleschi et al. (2014) conducted a multi-site research study at four hospitals in a for-profit, urban, tertiary care medical center using electronic medical records. The authors implemented an intervention that included interprofessional education to registered nurses, rapid response team, and physicians. A total of 150 patients met the following inclusion criteria: 1) patients at least 18 years old, 2) discharge diagnosis of sepsis, severe sepsis, or septic shock, 3) documentation by provider of sepsis, and 4) met sepsis definition. Patients with a do not resuscitate code status, inaccurate sepsis alert, and those who died within 12 hours of the sepsis alert were excluded from the study. Data was collected between 2010-2012 including Phase 1 $(n=50)$, Phase $2(n=47)$, and Phase $3(n=53)$ in which different interventions were implemented between each phase. Data for phase one was collected immediately after sepsis alert initiation, followed by phase two immediately before education, and then phase three was conducted post-intervention.

A statistically significant difference was found in improvements of the sepsis bundled strategies. There was a statistical significance between the groups in lactate 
completion $(x=16.9$ and $p<0.1)$. Between phases 2 and 3 , there was an improvement in mean time to antibiotic administration in minutes of $182.09(\mathrm{SD}=234)$ versus 92.6 $(\mathrm{ds}=168)$. There was a relationship between education and compliance with bundled interventions.

The authors concluded IPL and collaboration are necessary to facilitate compliance with the sepsis implementation strategies (Palleschi et al., 2014). Electronic surveillance of patients at risk for sepsis is a proactive approach to improve timeliness of interventions. The sepsis alert and educational tools were strategies to help staff to act timely and appropriately in improving outcomes.

Chung et al. (2015) designed an interprofessional sepsis education module for twenty-two participants including residents $(n=16)$, registered nurses $(n=4)$, and respiratory therapists $(\mathrm{n}=2)$. The study assessed knowledge and learning on the sepsis guidelines and interprofessional team behavior. The authors stated sepsis management requires many health care providers involved at different levels. The study used simulation, feedback, and group discussions to teach interprofessional team communication and collaboration on sepsis management.

There were significant improvements in pre- and post-knowledge test scores on the sepsis guidelines from $75 \%$ to $85 \%(\mathrm{p}<0.0001)$ between subspecialties and years of training. Participants reported improvement in collaborative behaviors and team communication in the evaluation and feedback of the program. 
Working professionals such as physicians, nurses, and respiratory therapists participated in learning about sepsis. However, the study did not assess their readiness to learn together. The authors used a formative assessment to evaluate the impact of the sepsis education program. The authors asserted learning modules about sepsis are an effective way to introduce IPL into any curriculum.

\section{Current State of IPL}

Meleis (2016) reviewed the current state of IPL and states that innovative teaching and learning strategies need to be congruent with the context and needs of the local populations. She further states that IPL should focus on patient and population centered models of care (Meleis, 2016). She points out that healthcare team members face strong barriers that are based in historical hierarchies and gender differences. She also defines a barrier identified in a previous study called "profession centrism" (Pecukonis, 2014, p. 60) This concept explains how each profession possesses its own identity, values, methods of learning, and practicing, unfortunately leading to a pride in their professional identity which leads to "elitism, territorialism, and isolation" (Meleis, 2016, p. 110). These behaviors stand in the way of IPL, learning, and collaboration between professions. These behaviors certainly could affect readiness to learn together.

\section{Studies using RIPLS}

Most research studies using the RIPLS questionnaire targeted mainly students (Bradley, Cooper, \& Duncan, 2009; Cusack et al., 2012; Hertweck et al., 2012;

Lachmann, Fossum, Johansson, Karlgren, \& Ponzer, 2014; Wakely, Brown, \& Burrows, 2013; Wicker, 2011). Despite the widespread use of RIPLS, few studies examine 
healthcare professionals' readiness to learn about sepsis. Barwell et al. (2013) points out that research is needed on the effects of IPL beyond undergraduate studies. 


\section{CHAPTER 3: METHODOLOGY}

\section{Project Design}

The study methodology is a descriptive, quantitative research design.

\section{Population and Sample}

A sample of subjects $(n=111)$ in this study included registered nurses $(n=52)$, physicians $(n=29)$, and respiratory therapists $(n=30)$ working in an acute care, community hospital in Northern California. The registered nurses were employed by the hospital and came from inpatient departments including direct care nurses from medical surgical departments, emergency department, and critical care units. The physicians were comprised from different specialties with active privileges and caring for patients at the community hospital. The respiratory therapists were active, inpatient acute care providers employed by the hospital.

\section{Demographic Variables}

The demographic variables collected in the study were age, gender, type of profession, and years of experience in profession.

\section{Sampling Procedures}

Approval to conduct the study was obtained from the hospital and academic institution's Institutional Review Boards. While participants of the study were not current students, they should be considered potential students and their attitudes were evaluated based on this assumption. This survey is appropriate to use for the study participants, because the questions relate to how ready the subjects are for interprofessional learning. Subjects were not compensated for their participation. 


\section{Investigative Interventions}

Although this study was done on human subjects, this was an education readiness study and not medical research. No special procedures were used.

\section{Instrumentation}

The data collection tool used was the Readiness for Interprofessional Learning Scale (RIPLS), a 19-item questionnaire, publicly available on the National Center for Interprofessional Practice and Education (2015) web-based collection (http://nexusipe.org). The RIPLS is widely used and a validated tool in assessing the readiness for interprofessional learning in healthcare professions students (McFayden et al., 2005). The RIPLS was selected to assess the differences in readiness of healthcare professionals in the community setting.

Parsell and Bligh (1999) originally developed the RIPLS scale to evaluate the attitudes and perceptions of students regarding interprofessional education. The original scale had 19 items with three subscales. Later, McFayden et al. (2005) divided the RIPLS into four subscales but also had 19 items, using the 5-point Likert scale. According to McFayden, Webster, and Maclaren (2006), test-retest reliability of the RIPLS was found to be acceptable for the subscales and individual items.

The RIPLS items are scored on a 5-point Likert-type scale to assess attitudes and readiness for interprofessional learning in regards to teamwork and collaboration, positive and negative professional identity, and professional roles. 
The RIPLS questionnaire has four sub scales:

1) Teamwork and Collaboration includes items \#1-9, total possible score of 45 . The item content represents the belief that shared learning is beneficial in many ways. A high score implies agreement regarding the importance of these qualities.

2) Negative Professional Identity - items \#10-12, total possible score of 15. A high score in this subscale implies negative perception of interdisciplinary learning with other professions. Two of the negatively worded questions in subscale 2 were reverse scored. Reverse score means that the scoring scale runs in the opposite direction. A higher score correlates with more readiness for interprofessional learning, which is consistent with the other subscales.

3) Positive Professional Identity - items \#13-16, total possible score of 20. A high score implies valuing shared learning experiences with other health professions.

4) Roles and Responsibilities - items \#17-19, total possible score of 15. A high score implies an unclear perception of one's own role and that of others.

\section{Validity}

Reid, Bruce, Allstaff, and McLernon (2006) found the RIPLS tool valid for use in the post-graduate level for assessing attitudes towards interprofessional learning. A group 
of health care experts examined the tool and factor analysis showed construct validity. Construct validity is the extent the measurement tool actually measures the intended theoretical concepts.

\section{Reliability}

Parsell and Bligh's (1999) original RIPLS instrument had a reliability measure of 0.76 and a Cronbach's alpha of 0.81 . The revised RIPLS version has a Cronbach's alpha of 0.9 (Reid et al., 2006).

\section{Variable List}

The independent variables in this study were age as a categorical variable, gender, type of profession, and years of experience. The dependent variables were readiness towards teamwork and collaboration, sense of positive professional identity, sense of negative professional identity, and roles and responsibilities.

\section{Data Collection}

After obtaining IRB approval, data collection commenced for one-month period of time until 111 surveys were received. Data collection occurred at a 359-bed community hospital in Northern California. Completion of the survey by the subject indicated implied consent. Hospital email was used to recruit subjects, introduce the study, and distribute the survey via an electronic link.

A paper survey was also available for participants who wished to complete by that method rather than electronically. Instructions to complete and return the survey to the researcher were given. Completed paper surveys were collected, placed in an envelope, and returned to the researcher. Completed paper surveys were kept in a locked office. The 
researcher manually entered the paper survey responses into Survey Monkey ${ }^{\mathrm{TM}}$. The electronic survey results were stored in a secure computer and only accessible by the principal investigator using a password.

Regardless of electronic or paper method, participation was voluntary. Participants completed the survey at their convenience and the estimated time to complete the survey was about 5 to 10 minutes. Confidentiality was maintained as data was coded and the responses were anonymous.

\section{Data Analysis Plan}

After data was collected and entered in Survey Monkey ${ }^{\mathrm{TM}}$ software, the data was exported in an Excel ${ }^{\mathrm{TM}}$ spreadsheet. The hospital biostatistician analyzed the data based on the research questions. All data was inputted and analyzed using the free software environment for statistical computing from the R Project ${ }^{\circledR}$ commonly referred to as R, version 3.1 .2 (n.d., https://www.r-project.org).

\section{Statistical Treatment}

A descriptive analysis was used to run the frequency of the data. The Kruskal Wallis, also called the one-way analysis of variance on ranks, is a non-parametric statistical test used to measure the association between the demographic variables and compare the three groups. Since the data is ordinal in nature and derived from the RIPLS Likert scale, the medians and ranges of the data were presented. The Chi-squared test and Fisher's Exact was used to test for statistical significance with a p-value set at 0.05 . 


\section{Ethical Consideration}

This low risk study had no social, physical, economic, legal, or psychological risk to participants. There were no violations of normal expectations. Although there were no risks to participants, the principal investigator informed and reminded subjects that participation in the study was voluntary and they could have withdrawn from the study at any time. 


\section{CHAPTER 4: RESULTS}

\section{Demographic Description}

The demographic variables are shown below in Table 1 .

Table 1

Demographics By Profession

\begin{tabular}{|c|c|c|c|c|c|}
\hline & & $\begin{array}{c}\text { Nurses } \\
(\mathrm{n}=52) \\
\%(n)\end{array}$ & $\begin{array}{c}\text { Physicians } \\
(\mathrm{n}=29) \\
\%(n)\end{array}$ & $\begin{array}{c}\text { Respiratory } \\
\text { Therapists } \\
(\mathbf{n}=30) \\
\%(n)\end{array}$ & p-value \\
\hline \multirow[t]{2}{*}{ Gender } & Female & $67.3 \%(35)$ & $58.6 \%(17)$ & $60 \%(18)$ & 0.68 \\
\hline & Male & $32.7 \%(17)$ & $41.4 \%(12)$ & $40 \%(12)$ & \\
\hline \multirow[t]{6}{*}{ Age } & $20-29$ & $5.8 \%(3)$ & $0 \%$ & $10 \%(3)$ & 0.21 \\
\hline & $30-39$ & $26.9 \%(14)$ & $34.5 \%(10)$ & $26.7 \%(8)$ & \\
\hline & $40-49$ & $25 \%(13)$ & $17.2 \%(5)$ & $36.7 \%(11)$ & \\
\hline & $50-59$ & $28.9 \%(15)$ & $31.0 \%(9)$ & $26.7 \%(8)$ & \\
\hline & $60+$ & $13.5 \%(7)$ & $13.8 \%(4)$ & $0 \%$ & \\
\hline & Missing & $0 \%$ & $3.5 \%(1)$ & $0 \%$ & \\
\hline \multirow{7}{*}{$\begin{array}{l}\text { Years of } \\
\text { Experience }\end{array}$} & $0-5$ & $15.4 \%(8)$ & $13.8 \%(4)$ & $20 \%(6)$ & 0.45 \\
\hline & $6-10$ & $13.5 \%(7)$ & $24.1 \%(7)$ & $30 \%(9)$ & \\
\hline & $11-20$ & $28.9 \%(15)$ & $17.2 \%(5)$ & $20 \%(6)$ & \\
\hline & $21-30$ & $17.3 \%(9)$ & $27.6 \%(8)$ & $20 \%(6)$ & \\
\hline & $31-40$ & $17.3 \%(9)$ & $10.3 \%(3)$ & $10 \%(3)$ & \\
\hline & $41+$ & $7.7 \%(4)$ & $3.5 \%(1)$ & $0 \%$ & \\
\hline & Missing & $0 \%$ & $3.5 \%(1)$ & $0 \%$ & \\
\hline
\end{tabular}


Of the 111 participants, almost two-thirds of the survey participants were female $(n=70) .84 \%$ of the participants were between the ages of $30-59$ years, $24 \%$ of the participants had between 11-20 years experience, followed by $21 \%$ at both $6-10$ years and at 21-30 years. There were no statistically significant differences in demographics between the different professions.

\section{Overall Readiness Level}

The median RIPLS total score for all the groups was 72 (sample's range $=58-81$, out of a total possible range: 19-95). The median Teamwork/Collaboration (TC) score was 35 (sample's range $=24-39$, out of total possible range: $5-45$ ). The median Negative Professional Identity (NPI) score was 11 (sample's range $=5-15$, out of total possible range: 3-15). The median Positive Professional Identity (PPI) score was 16 (sample's range $=8-19$, out of possible range: $4-20$ ). The median Roles/Responsibility (RR) score was: 11 (sample's range $=7-15$, out of total possible range: $3-15$ ). There were no statistically significant associations between the demographic characteristics and any of the subscales.

When comparing the readiness levels among the different demographic groups (Table 2), there were no statistically significant differences (p-value $>1.0$ ) in the four subscales and the RIPLS total score. 
Table 2

Readiness Level: Comparing Different Demographic Groups

\begin{tabular}{lllllll}
\hline & & $\begin{array}{l}\text { TC } \\
\text { Median } \\
(\text { Range })\end{array}$ & $\begin{array}{c}\text { Nedian } \\
\text { (Range })\end{array}$ & $\begin{array}{c}\text { Median } \\
\text { (Range) }\end{array}$ & $\begin{array}{c}\text { Redian } \\
\text { Range })\end{array}$ & $\begin{array}{c}\text { RIPLS } \\
\text { Total Score } \\
\text { Median } \\
\text { Range })\end{array}$ \\
\hline Gender & Female & $35(28-39)$ & $11(5-14)$ & $16(12-19)$ & $11(7-15)$ & $72(62-81)$ \\
\hline $\begin{array}{l}\text { Age } \\
\text { (In Years) }\end{array}$ & Male & $36(24-39)$ & $11(7-15)$ & $16(8-19)$ & $11(8-15)$ & $73(58-80)$ \\
& $30-29$ & $35.5(31-39)$ & $10(7-11)$ & $16(15-16)$ & $11.5(9-14)$ & $71(67-77)$ \\
& $40-49$ & $36(31-38)$ & $11(8-15)$ & $16(10-19)$ & $11(8-15)$ & $74(59-81)$ \\
& $50-59$ & $36(24-39)$ & $11(5-14)$ & $16(12-18)$ & $11.5(8-15)$ & $73(58-79)$ \\
& $60+$ & $36(30-36)$ & $11(7-12)$ & $16(14-17)$ & $11(7-13)$ & $72(65-76)$ \\
\hline $\begin{array}{l}\text { Years of } \\
\text { Experience }\end{array}$ & $0-5$ & $36(30-39)$ & $10.5(7-15)$ & $16(10-19)$ & $11(8-15)$ & $73(59-80)$ \\
& $6-10$ & $35(30-36)$ & $11(7-12)$ & $16(14-18)$ & $11(8-15)$ & $73(65-78)$ \\
& $11-20$ & $35.5(30-36)$ & $10.5(5-15)$ & $16(13-19)$ & $11(8-15)$ & $72.5(62-81)$ \\
& $21-30$ & $35(24-39)$ & $11(7-13)$ & $16(12-16)$ & $11(8-15)$ & $73(58-79)$ \\
& $31-40$ & $35(30-36)$ & $11(7-14)$ & $16(12-17)$ & $11(7-14)$ & $70(65-78)$ \\
& $41+$ & $36(35-36)$ & $11(10-11)$ & $16(14-17)$ & $11(8-13)$ & $73(69-76)$ \\
\hline
\end{tabular}

There were no significant differences in readiness level (both overall, and for any subscales) between the different specialty groups (Table 3). Nurses' RIPLS total score was 73 , the highest overall. The RIPLS total score overall for physicians were 71 and respiratory therapists were 71.5. Nurses tended to agree more about the importance of 
teamwork and collaboration $(\mathrm{Mdn}=36)$ compared to physicians' $(\mathrm{Mdn}=35)$ and respiratory therapists' $(\mathrm{Mdn}=34)$.

Table 3

Readiness Level: Comparing Registered Nurses, Physicians, and Respiratory Therapists

\begin{tabular}{lcccc}
\hline RIPL Subscales & $\begin{array}{c}\text { Registered } \\
\text { Nurses } \\
\mathbf{( n = 5 2 )} \\
\text { Median } \\
(\text { Range })\end{array}$ & $\begin{array}{c}\text { Physicians } \\
\mathbf{( n = 2 9 )} \\
\text { Median } \\
(\text { Range })\end{array}$ & $\begin{array}{c}\text { Respiratory } \\
\text { Therapists } \\
\mathbf{( n = 3 0 )} \\
\text { Median } \\
\text { (Range) }\end{array}$ & $\begin{array}{c}\text { p- } \\
\text { value }\end{array}$ \\
\hline$T C$ & $36(28-38)$ & $35(24-39)$ & $34(28-39)$ & 0.33 \\
NPI & $11(7-15)$ & $11(5-13)$ & $11(7-13)$ & 0.96 \\
$P P I$ & $16(12-19)$ & $16(8-18)$ & $16(12-18)$ & 0.48 \\
$R R$ & $11(8-15)$ & $11(7-14)$ & $11(8-15)$ & 0.53 \\
\hline RIPLS Total Score & $\mathbf{7 3 ( 6 2 - 8 1 )}$ & $\mathbf{7 1 ( 5 8 - 7 8 )}$ & $\mathbf{7 1 . 5 ( 6 3 - 8 0 )}$ & $\mathbf{0 . 2 6}$ \\
\hline
\end{tabular}

None of the other specific subscale questions (other than teamwork/collaboration) showed significant differences by specialties. There was statistical significance (p-value 0.02) for question number nine, "for small group learning to work, professionals need to respect and trust each other". RTs had variation in opinion compared to MDs and RNs irrespective of age, gender, or years of experience in the teamwork and collaboration subscale questions. 


\section{CHAPTER 5: DISCUSSION}

Learning and education is a lifelong, continuous process necessary for clinicians to develop knowledge, attitudes, and behaviors focused on quality improvement and patient safety. According to Weaver, Rosen, Salas, Baum, and King (2010), practical learning experiences shape learner's perceptions of professional norms, values, and behavior. The interprofessional approaches to learning spans disciplinary and professional boundaries in the continuing education context (Weaver et al., 2010).

\section{Implications for Practice}

Opportunities for formal and informal implementation of IPL exist in the workplace and should be relevant to all learners (McKimm \& Brake, 2010). IPL creates a collaborative and safe environment to identify roles, share knowledge, and manage learning activities. IPL can be used to engage learners to enhance interprofessional team communication and collaboration. Pitt et al. (2014) successfully implemented IPL in a community hospital setting and concluded IPL should be integrated in clinical practice to improve working relationships and teamwork.

This quantitative study measured the readiness level for interprofessional learning between the healthcare providers in the acute care setting. The findings established a baseline assessment of readiness level towards IPL for different professional groups. This study reveals nurses, physicians, and respiratory are ready for interprofessional learning as indicated by the higher median total RIPLS scores overall and for each of the subscales. 
Results of this study are consistent with previous studies where students were ready to engage in IPL (Rossler \& Kimble, 2016). However, there was no statistically significant relationship between age, gender, years of experience and readiness levels for each profession and overall. These findings suggest there are fewer barriers to overcome when implementing IPL in the study setting. Also, a positive learning and work environment for collaboration is encouraged by the results of this study.

This project conclusion affirms the unique nature of the workforce in the workplace strongly influences the perceptions of interprofessional learning (Owen et al., 2014). The interprofessional team needs to learn and understand their roles and responsibilities, professional identities, and collaborative team practice. In this study, respiratory therapists' opinions varied in regards to respect and trust with other professions in the teamwork and collaboration subscale. Respiratory therapists perception of equal empowerment needs to be explored further.

\section{Limitations}

This study looked at the associations, but the cross sectional survey does not infer causation. The sample sizes for physicians, nurses, and respiratory therapists were not equal, with registered nurses outnumbering MDs and RTs individually at almost 2:1.

Different levels of education preparation influence experience with IPL. To explain, learning is progressively built upon the early foundations of professional development in the undergraduate and graduate education (Weaver et al., 2010). However, academic degrees were not adjusted, since this demographic data was not collected. 
Another limitation is the possibility of selection bias, because the population was a convenience sample. Another potential bias is the subjects completing the survey knew the principal investigator who worked at the same hospital. Many studies in the literature were conducted at large, academic institutions on health professions students. This study was conducted at a single site and limits generalizability of the findings.

\section{Conclusion}

In conclusion, there are opportunities for interprofessional teams to collaborate in learning to develop mutual solutions for complex healthcare problems such as sepsis (Meleis, 2016). Professional practice is enhanced and quality of care is improved, when involving learners from different professions to learn together. Clinical education programs should include multiple professionals learning together to provide insight into processes through shared learning and collaboration. This study paves the groundwork to transform how healthcare professionals are educated to address the emerging needs and healthcare challenges.

A suggestion for future research is to replicate this study with a larger sample at different sites and settings with equal sample size of the various professions included. Also, a longitudinal study evaluating any changes in readiness to learn compared with pre- and post-interventions on the impact of IPL on multi-disciplinary collaboration and patient outcomes would be suggested. Qualitative interviews can explore attitudes and beliefs related to respect and trust in teamwork/collaboration to more robustly capture the readiness for IPL. More research needs to be done investigating IPL in terms of sepsis education and the impact on sepsis patient outcomes. 


\section{REFERENCES}

Akella, D. (2010). Learning together: Kolb’s experiential theory and its application. Journal of Management and Organization, 16, 100-112.

Bajnok, I., Puddester, D., MacDonald, C., Archibald, D., \& Kuhl, D. (2012).

Building positive relationships in healthcare: Evaluation of the teams of interprofessional staff interprofessional education program. Contemporary Nurse, 42(1), 76-89.

Barwell, J., Arnold, F., \& Berry, H. (2013). How interprofessional learning improves care. Nursing Times, 109(21), 14-16.

Billings, D., \& Halstead, J. (2012). Teaching in nursing: A guide for faculty. St. Louis, MO: Elsevier Saunders.

Bradley, P., Cooper, S., \& Duncan, F. (2009). A mixed-methods study of interprofessional learning of resuscitation skills. Medical Education, 43(9), 912922.

Center for the Advancement of Interprofessional Education (CAIPE) (2002). Interprofessional education: A definition. Retrieved from http://www.caipe.org.uk Centers for Medicare and Medicaid Services. (2014). Retrieved from http://www.cms.org

Chung, H., Medina, D., \& Fox-Rochichaud, A. (2015). Interprofessional sepsis education module: A pilot study. Canadian Journal of Emergency Medicine, 1-3. doi: $10.1017 / \mathrm{cem} .2015 .42$ 
Cooke C.R, \& Iwashyna, T.J. (2014). Sepsis mandates: Improving inpatient care while advancing quality improvement. JAMA, 312(14):1397-1398. doi:10.1001/jama.2014.11350

Cusack, T., O'Donoghue, G., Butler, M., Blake, C., O'Sullivan, C., Smith, K., ... O’Neill, G. (2012). A pilot study to evaluate the introduction of an interprofessional problem-based learning module. Interdisciplinary Journal of Problem-based Learning, 6(2), 31-45.

Hean, S., Craddock, D., \& O’Halloran, C. (2009). Learning theories and interprofessional education: A user's guide: Learning theories and interprofessional education. Learning in Health and Social Care, 8(4), 250-262.

Hertweck, M., Hawkins, S., Bednarek, M., Goreczny, A., Schreiber, J., \& Sterrett, S. (2012). Attitudes toward interprofessional education: Comparing physician assistant and other health care professions students. The Journal of Physician Assistant Education: The Official Journal of the Physician Assistant Education Association, 23(2), 8.

Institute of Healthcare Improvement. (2016). IHI Triple Aim. Retrieved from http:/www.ihi.org

Institute of Medicine. (2010). The future of nursing: Leading change, advancing health. Retrieved from http://www.nationalacademies.org/hmd/Reports/2010/The-Futureof-Nursing-Leading-Change-Advancing-Health.aspx

Kolb, D. (1984). Experiential learning: Experience as the source of learning and development. Englewood Cliffs, NJ: Prentice Hall. 
Lachmann, H., Fossum, B., Johansson, U., Karlgren, K., \& Ponzer, S. (2014). Promoting reflection by using contextual activity sampling: a study on students' interprofessional learning. Journal of Interprofessional Care, 28(5), 400-406. doi:10.3109/13561820.2014.907777

Levy, M., Dellinger, P., \& Townsend, S., Linde-Zwirble, W., Marshall, J., Bion, J., ... Angus, D. (2010). The Surviving Sepsis Campaign: Results of an international guideline-based performance improvement program targeting severe sepsis. Critical Care Medicine, 38(2), 367-374.

Lopez-Bushnell, K., Demaray, W., \& Jaco, C. (2014). Reducing sepsis mortality. Medsurg Nursing: Official Journal of the Academy of Medical-Surgical Nurses, 23(1), 9-14.

McFadyen, A., Webster, V., \& Maclaren, W. (2006). The test-retest reliability of a revised version of the readiness for interprofessional learning scale (RIPLS). Journal of Interprofessional Care, 20(6), 633-639.

McFayden, A.K., Webster, V., Strachan, K., Figgins, E., Brown, H., \& McKenchie, J. (2005). The readiness for interprofessional learning scale: A possible more stable sub-scale model for the original version of RIPLS. Journal of Interprofessional Care, 19(6), 595-603. Retrieved from http://dx.doi.org/10.1080/13561820500430157

McKimm, J., \& Brake, D. (2010). Interprofessional learning. British Journal of Hospital Medicine, 71(10), 580-583. 
Meleis, A.I. (2016). Interprofessional education: A summary of reports and barriers to recommendations. Journal of Nursing Scholarship, 48(1), 106-112.

National Academy of Medicine. (2011-2013). Global forum on innovation in health professional education. Retrieved from https://www.iom.nationalacademies.org/Activities/Global/InnovationHealthProfE ducation.aspx

National Academy of Medicine. (2013). Establishing transdisciplinary professionalism for improving health outcomes - Workshop summary. Global Forum on Innovation in Health Professional Education. Retrieved from https://www.iom.nationalacademies.org/Reports/2013/EstablishingTransdisciplinary-Professionalism-for-Improving-Health-Outcomes.aspx National Academy of Medicine. (2015). Measuring the impact of interprofessional education (IPE) on collaborative practice and patient outcomes. Global Forum on Innovation in Health Professional Education. Retrieved from https://www.iom.nationalacademies.org/Reports/2015/Impact-of-IPE.aspx National Center for Interprofessional Practice and Education. (2015). Retrieved from https://nexusipe.org

Owen, J.A, Brashers, V., Littlewood, K.E., Wright, E., Childress, R.M, \& Thomas, S. (2014). Designing and evaluating an effective theory-based continuing interprofessional education program to improve sepsis care by enhancing healthcare team collaboration. Journal of Interprofessional Care, 28(3), 212-217. doi: $10.3109 / 13561820.2014 .890581$ 
Palleschi, M., Sirianni, S., O'Connor, N., Dunn, D., \& Hasenau, S. (2014). An interprofessional process to improve early identification and treatment for sepsis. Journal for Healthcare Quality: Official Publication of the National Association for Healthcare Quality, 36(4), 23-31.

Parsell, G., \& Bligh, J. (1999). The development of a questionnaire to assess the readiness of health care students for interprofessional learning (RIPLS). Medical Education, 33(2), 95-100. http://dx.doi.org/10.1046/j.1365-2923.1999.00298.x

Pecukonis, E. (2014). Interprofessional education: A theoretical orientation incorporating profession-centrism and social identity theory. Journal of Law, Medicine, \& Ethics, 42(Suppl. 2), 60-64.

Pitt, M., Kelley, A., \& Carr, J. (2014). Implementing interprofessional learning in the community setting. British Journal of Community Nursing, 19(6), 291-296.

Puente, A.E. (2015). The Journal of Interprofessional Education \& Practice: The future of healthcare today. Journal of Interprofessional Education \& Practice, 3-4. Retrieved from http://dx.doi.org/10.1016/j.xjep.2015.03.006

Reeves, S., Perrier, L., Goldman, J., Freeth, D., \& Zwarenstein, M. (2013). Interprofessional education: Effects on professional practice and healthcare outcomes (update). Cochrane Database of Systematic Reviews, Issue 1. Art. No.: CD002213. doi:10.1002/14651858.CD002213.pub3 
Reid, R., Bruce, D., Allstaff, K., \& McLernon, D. (2006). Validating the Readiness for Interprofessional Learning Scale (RIPLS) in the postgraduate context: Are health care professionals ready for IPL? Medical Education, 40, 415-422. doi: $10.1111 / \mathrm{j} .1365-2929.2006 .02442 . x$

Rossler, K., \& Kimble, L. (2016). Capturing readiness to learn and collaboration as explored with an interprofessional simulation scenario: A mixed-methods research study. Nurse Education Today, 36, 348-353.

R-Project for Statistical Computing. (n.d.). Retrieved from https://www.r-project.org Singer, M., Deutschman, C., Seymour, C., Shankar-Hari, M., Annane, D., Bauer, M., ... Angus, D. (2016). The Third International Consensus Definitions for Sepsis and Septic Shock (Sepsis-3). JAMA, 315(8), 801-810. doi:10.1001/jama.2016.0287.

Sollami, A., Caricati, L., \& Sarli, L. (2015). Nurse-physician collaboration: A meta -analytical investigation of survey scores. Journal of Interprofessional Care, 29(3), 223-229.

Soo Hoo, W., Muehlberg, K., Ferraro, R., \& Jumaoas, M. (2009). Successes and lessons learned implementing the sepsis bundle. Journal for Healthcare Quality, 31(4), 915.

Wakely, L., Brown, L., \& Burrows, J. (2013). Evaluating interprofessional learning modules: Health students' attitudes to interprofessional practice. Journal of Interprofessional Care, 27(5): 424-425. 
Weaver, S., Rosen, M., Salas, E., Baum, K., \& King, H. (2010). Integrating the science of team training: Guidelines for continuing education. Journal of Continuing Education In The Health Professions, 30(4), 208-220. DOI: 10.1002/chp.20085

Wicker, P. (2011). Interprofessional learning. Journal of Perioperative Practice, 21(3), 83.

World Health Organization (2010). Framework for action on interprofessional education and collaborative practice. Retrieved from http://www.who.int/hrh/resources/framework_action/en 